\title{
Synthesis and characterization of a high performance polycarboxylic acid water reducing agent
}

\author{
Qiong Yan ${ }^{1 *}$,Liangke $\mathrm{Yao}^{1}$, Yongzhong Xia ${ }^{1}$, Shishan Liu ${ }^{1}$, Lingcong Chen ${ }^{1}$ \\ ${ }^{1}$ Hunan Prominent Science New Materials Co. Ltd. Xiangtan, Hunan, China.
}

\begin{abstract}
The optimal synthesis process conditions of polycarboxylic acid water reducers were investigated and characterized by infrared spectroscopy as well as GPC using high performance polycarboxylic acid water reducers synthesized by isoproterenol polyoxyethylene ether polymerized with acrylic acid and introducing unsaturated monomeric dibasic ester. The results showed that the optimum synthetic process conditions were as follows: acid-ether ratio of 3.0:1, amount of binary ester as $2.8 \%$ of monomer mass, amount of initiator as $0.35 \%$ of monomer mass, amount of chain transfer agent as $0.35 \%$ of monomer mass; the initial slump and initial expansion of the concrete of the synthetic water-reducing agent PCE-H were greater than those of the commercially available polycarboxylic acid water-reducing agent PCE-W, and the working performance of the concrete was better. PCE-H also has no adverse effect on strength.
\end{abstract}

\section{Introduction}

With the deepening of urbanization construction, the construction industry has been rapid development, and as the main building materials of concrete and its auxiliary products, the demand for concrete admixtures is also increasing. The use of high performance polycarboxylic acid water-reducing agents is especially important to meet the demand for high performance concrete in various projects. Therefore, the development and utilization of high performance polycarboxylic acid water reducing agents and other concrete additives has become a research hotspot ${ }^{[1-6]}$.

In this paper, through the free radical polymerization reaction, unsaturated ester monomers were introduced, and a high performance polycarboxylate water-reducing agent with good compatibility was studied through the best process ratio, and characterized by infrared spectroscopy and a series of gel chromatography.

\section{Experimental}

\subsection{Experimental raw materials.}

Isopentenyl polyoxyethylene polyether (TPEG, $\mathrm{Mw}=$ $2400 \mathrm{~g} / \mathrm{mol}$, industrial grade), acrylic acid (AA, industrial grade), hydrogen peroxide $\left(\mathrm{H}_{2} \mathrm{O}_{2}, 27.5 \mathrm{wt} \%\right.$, industrial grade), binary ester (industrial grade), mercaptoacetic acid (95\% aqueous solution, industrial grade), L-Ascorbic acid (industrial grade), sodium hydroxide solution $(32 \%$ aqueous solution, industrial grade).

\subsection{Test raw materials.}

Cement (C, Qizhiqiao brand, P.O 42.5R), strait sand River sand (2.8 fineness modulus, less than $1 \%$ sediment content)), gravel (G1, the grain size of $10-20 \mathrm{~mm}$ ), tap water met the test requirements, PCE-W is a commercially available high performance polycarboxylic acid water reducer with $39 \%$ solid content, while PCE-H is a high performance polycarboxylic acid water reducer synthesized in a laboratory with $39 \%$ solid content.

\subsection{Copolymerization of PCE-H.}

Add measured TPEG macromonomers, hydrogen peroxide and water into a $1000 \mathrm{ml}$ four-mouth flask, turn on the stirrer, wait until the macromonomers are dissolved, then start adding the mixture of acrylic acid, glyceryl maleic anhydride and water (A), L-type ascorbic acid and water (B), mercaptoacetic acid and water (C). The reaction is continued for 1 hour after the titration. After the dropping, continue the reaction for 1 hour, then add sodium hydroxide solution and neutralize to $\mathrm{pH}$ 6-7, that is, get a high performance polycarboxylic acid water reducing agent product.

\subsection{Performance test method}

\subsubsection{Fluidity of cement paste.}

The fluidity of cement paste is tested according to GB/T8077-2012 "Test method for homogeneity of

\footnotetext{
* Corresponding author: 1362797234@qq.com
} 
concrete admixtures". The water-cement ratio is 0.29 and the polycarboxylate superplasticizer content is $0.35 \%$.

\subsubsection{Concrete test.}

The concrete test is conducted according to GB/T500802016 "Standard Test Methods for Performance of Common Concrete Mixtures" and GB/T 50081-2002 "Standard Test Methods for mechanical properties of Common Concrete". Test the performance of concrete mixtures and hardened concrete. The concrete test mix proportion $(\mathrm{kg} / \mathrm{m} 3)$ was shown in Table 1.

Table 1. The concrete test mix proportion $\left(\mathrm{kg} / \mathrm{m}^{3}\right)$.

\begin{tabular}{cccc}
\hline $\mathrm{C}$ & $\mathrm{S}$ & $\mathrm{G}$ & $\mathrm{W}$ \\
\hline 380 & 880 & 1120 & 165 \\
\hline
\end{tabular}

\subsubsection{Gel permeation chromatographic (GPC) measurement.}

GPC was measured and analyzed by using American Waters 1515 Isocratic HPLP pump/glassed of water 2414 differential detector.

\subsubsection{Fourier transformer infrared spectra (FTIR) measurement.}

PCE-H were pressed disc with $\mathrm{KBr}$ to obtain FTIR data, respectively.

\section{Experimental results and discussion}

\subsection{Effect of acid ether ratio on dispersion of water reducing agent}

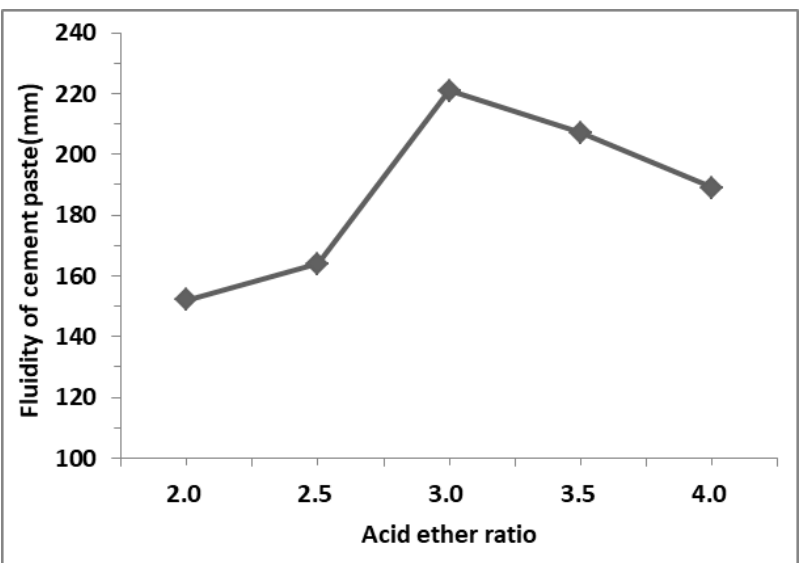

Figure 1. Effect of acid ether ratio on dispersion of water reducing agent.

Figure 1 shows the fluidity performance of polycarboxylate superplasticizer with different acid ether ratio. It can be seen from the figure that with the increase of acid ether ratio, the paste flow of the water reducer first increases and then decreases, and reaches the maximum value of $221 \mathrm{~mm}$ when the acid ether ratio is 3.0. The reason is that the carboxyl group in polycarboxylate superplasticizer will affect the molecular conformation, thus affecting the adsorption behavior of polycarboxylate superplasticizer on the cement surface. If the content of carboxyl group is too high, the molecular chain will curl up, and a part of carboxyl group will be wrapped in the molecular chain, which will reduce the contact area with cement particles, and then affect the dispersion of cement.

\subsection{Effect of amount of binary ester on dispersion of water reducing agent}

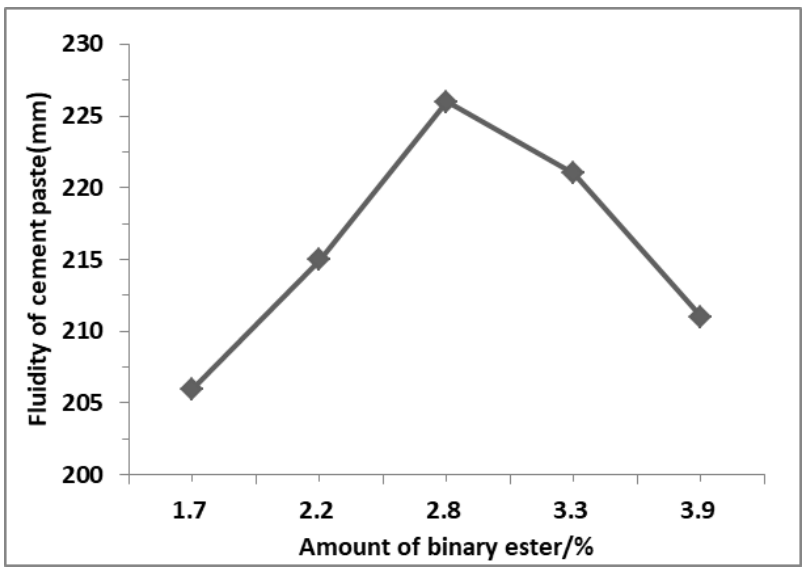

Figure 2. Effect of amount of binary ester on dispersion of water reducing agent.

It can be seen from Figure 2 that the fluidity of cement paste with water reducer increases at first and then decreases with the increase of the amount of binary ester. When the amount of binary ester is $2.8 \%$ of monomer mass, the fluidity of cement paste reaches the maximum value of $226 \mathrm{~mm}$. This is due to the hydrolysis of ester bond (- COOR) in binary ester in alkaline environment, which provides carboxylate ions in cement paste continuously to achieve the effect of dispersing cement particles. However, excessive addition of binary esters will lead to excessive carboxyl groups, resulting in excessive repulsion between charges, which will affect the dispersion performance.

\subsection{Effect of initiator on dispersion of water reducing agent}

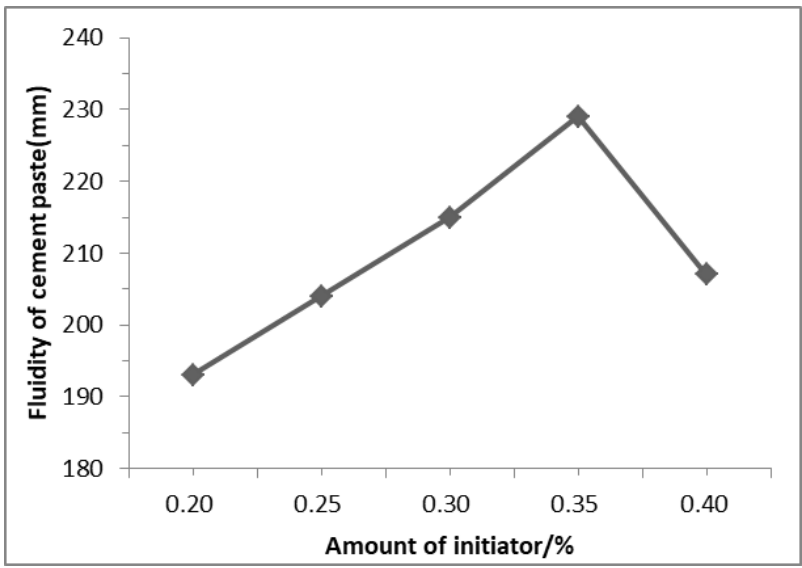

Figure 3. Effect of initiator on dispersion of water reducing agent. 
As shown in Figure 3, with the increase of the amount of initiator, the fluidity of the paste increases at first and then decreases. The optimal dosage of initiator is $0.35 \%$, and the maximum fluidity reaches $229 \mathrm{~mm}$. When the dosage exceeds the optimal amount, the fluidity of the paste shows a downward trend. The reason for this phenomenon is that, at a certain temperature, when the amount of initiator increases, the conversion of monomer increases, the effective content of water reducer in mother liquor increases, and the water reducing rate increases. When the initiator is too much, the molecular weight will be reduced, the length of the main chain will be shortened, and the water reduction rate will be reduced.

\subsection{Effect of chain transfer agent dosage on dispersion of water reducing agent}

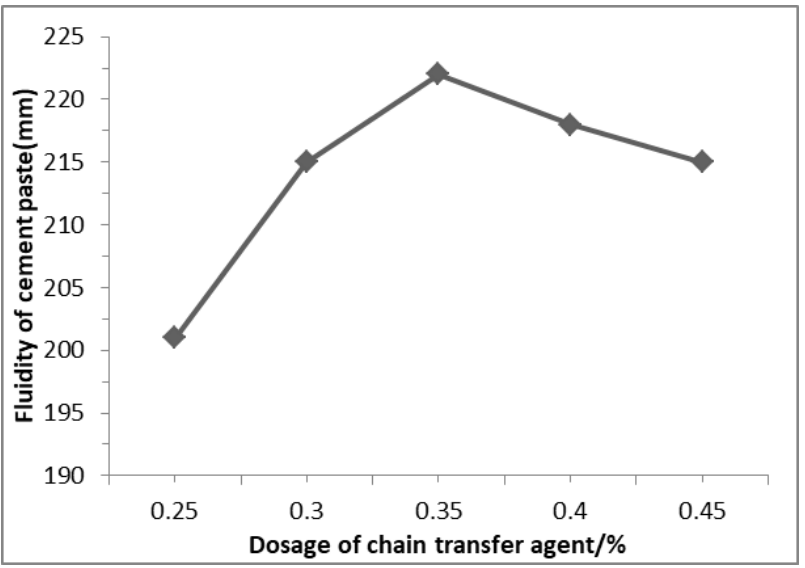

Figure 4. Effect of chain transfer agent dosage on dispersion of water reducing agent.

As shown in Figure 4, with the increase of chain transfer dosage, the net slurry flow of water-reducing agent shows a tendency of increasing and then decreasing. When the chain transfer agent is $0.35 \%$, the water reducing agent's net slurry flow is the largest. Water reducing agent needs the right amount of chain transfer agent, so as to achieve a certain molecular weight and molecular weight distribution. If the chain transfer agent is too little, the molecular chain cannot be transferred in time during the polymerization process, and the molecular weight is large, which affects the migration and diffusion of the water reducing agent molecules to the cement particles; if there is too much chain transfer agent, the main chain of molecules becomes shorter, the polymerized large monomer becomes less, the space potential resistance effect decreases, and the dispersing effect on the cement particles decreases.

\subsection{Concrete test}

In this paper, a comparative concrete performance test was conducted using the commercially available polycarboxylic acid water-reducing agent PCE-W and the synthetic high-performance polycarboxylic acid water-reducing agent PCE-H. The concrete experimental results are shown in Table 2.
Table 2. Concrete test results.

\begin{tabular}{|c|c|c|c|c|c|c|}
\hline \multirow{2}{*}{ Sample } & \multirow{2}{*}{$\begin{array}{c}\text { Dosag } \\
\text { e } / \%\end{array}$} & \multirow{2}{*}{$\begin{array}{l}\text { Slump } \\
\text { / mm }\end{array}$} & \multirow{2}{*}{$\begin{array}{l}\text { Dispersion } \\
\quad / \mathrm{mm}\end{array}$} & \multicolumn{3}{|c|}{$\begin{array}{l}\text { Compressive } \\
\text { strength / MPa }\end{array}$} \\
\hline & & & & $3 d$ & $7 \mathrm{~d}$ & $28 \mathrm{~d}$ \\
\hline PCE-W & 1.3 & 210 & 575 & 17.5 & 27.1 & 40.4 \\
\hline PCE-H & 1.3 & 220 & 590 & 18.3 & 28.7 & 41.2 \\
\hline
\end{tabular}

According to Table 2, it can be seen that at the same admixture, the synthetic PCE-H has greater slump and extension and better concrete workability compared with the market high performance polycarboxylic acid water reducing agent PCE-W. In terms of strength, PCE-H has slightly higher strength than the market water-reducing agent PCE-W, indicating that the water-reducing agent has no adverse effect on the strength of concrete.

\section{GPC measurement}

Table 3 was gel permeation chromatography data of PCE-W and PCE-H respectively.

Table 3. Gel permeation chromatographic data.

\begin{tabular}{ccccc}
\hline $\begin{array}{c}\text { Type of water } \\
\text { reducing agent }\end{array}$ & $\mathrm{M}_{\mathrm{n}}$ & $\mathrm{M}_{\mathrm{w}}$ & $\mathrm{M}_{\mathrm{w}} / \mathrm{M}_{\mathrm{n}}$ & $\begin{array}{c}\text { Conversion } \\
\text { rate } / \%\end{array}$ \\
\hline PCE-W & 23341 & 54384 & 2.33 & 85.42 \\
PCE-H & 23783 & 57792 & 2.43 & 88.31 \\
\hline
\end{tabular}

According to the data in Table 3, the average relative molecular mass of PCE-H is 23783, slightly larger than that of PCE-W 23341, the polydispersity coefficient is 2.43 , and the conversion rate is $88.31 \%$, slightly higher than that of PCE-W, the high-performance water reducing agent.

\section{FTIR measurement}

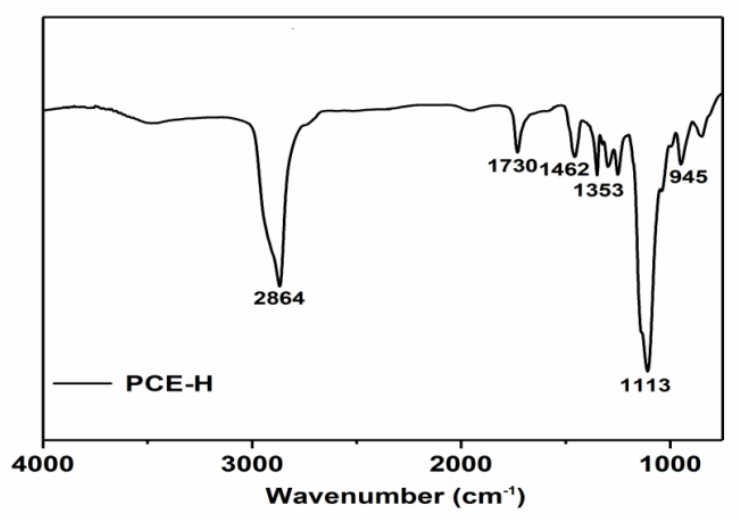

Figure 5. Infrared spectrogram.

According to Figure 5, it can be seen that the spikes at $2864 \mathrm{~cm}^{-1}$ are characteristic absorption peaks of methyl ($\mathrm{CH}_{3}$ ); at $1730 \mathrm{~cm}^{-1}$ are characteristic absorption peaks of $-\mathrm{C}=\mathrm{O}-$, which may be introduced ester group $(-\mathrm{C}=\mathrm{O}-)$ or carboxyl group $(-\mathrm{COOH})$; at $1353 \mathrm{~cm}^{-1}, 1460 \mathrm{~cm}^{-1}$ are characteristic absorption peaks of methylene- $\mathrm{CH}_{2}-$ bending vibrations; The absorption peaks at $1113 \mathrm{~cm}^{-1}$ and $945 \mathrm{~cm}^{-1}$ are characteristic of long side chain polyoxyethylene ethers, with the strongest absorption peak near $1107 \mathrm{~cm}^{-1}$ being the absorption peak of the 
ether bond $\mathrm{C}-\mathrm{O}-\mathrm{C}$, and $945 \mathrm{~cm}^{-1}$ being the stretching vibration peak of $\mathrm{C}-\mathrm{O}$. The presence of these absorption peaks indicates that the synthesized sample contains polyoxyethylene, carboxyl, ester, and ether groups, and the molecular structure of the product is basically consistent with the molecular structure of the designed water reducing agent.

\section{Conclusions}

(1) The best synthesis process for high performance polycarboxylic acid water reducing agent under room temperature using polyether TPEG is as follows: acidether ratio is $3.0: 1$, dosage of dibasic ester is $2.8 \%$ of the monomer, dosage of initiator is $0.35 \%$ of the monomer, dosage of chain transfer agent is $0.35 \%$ of the mass of the monomer.

(2) The high performance polycarboxylic acid water reducer PCE-H was characterized by infrared spectroscopy and gel chromatography, and the molecular structure of the product was consistent with the designed water reducer molecular structure.

(3) In the comparison test with PCE-W, the initial slump and initial expansion of PCE-H were significantly better than that of PCE-W, and its strength was slightly higher than that of PCE-W, with no adverse effect on the concrete.

\section{Acknowledgments}

Thanks for the support provided by Hunan Prominent Science New Materials Co. Ltd., and the anonymous reviewers for their careful review and suggestions.

\section{References}

1. Deng L, Jiang Y, Zhang B W, Shen J R, Luo X F. ( 2019 ) Development and application of superplasticizer of high and easy polycarboxylic acid. New Building Materials, 46(01):120-123..

2. Zhu Y B, Cao D Y,Li S X. ( 2015) Synthesistechnology research of high performance polycarboxylate superplasticizer in the room temperature. FLY ASH COMPREHENSIVE UTILIZATION, (05):39-40+48.

3. Xu Y D, Yin P, Wang P, Sun L, Bao S W. (2017) Room temperature synthesis of polycarboxylic acid water reducing agent by redox-initiated system. New Building Materials ,44 (07):17-20..

4. Jiang Z J, Chen XS, Zhong L N, Fang Y H, Chen X L, You R L. (2017) Effect of acrylic acid dosage on the structure and performance of polycarboxylic acid water reducing agent. New Building Materials, 44 (01):86-88+96.

5. Zhang S Y, Cao Q Y. ( 2018 ) Influence of molecular weight and conformation of polycarboxylic acid water reducing agent on its performance. Construction Technology, (04):100101.

6. TIAN W, ZHANG J, FU Y. (2015) Effect of relative molecular mass of polycarboxylic acid water reducing agent and its distribution on its performance. Shanghai Chemical Industry,40(12):4-6. 